\title{
Erfahrungen im Grenzbereich
}

Unsere Wohlstandsgesellschaft zeichnet sich unter anderem dadurch aus, dass sie es sich leisten kann, die Risiken des Lebens mit perfektionistischer Akribie systematisch aufzuspüren und zu eliminieren, zumindest aber zu minimieren. Ganze Branchen leben davon, das Leben sicherer zu machen und uns unliebsame Überraschungen vom Hals zu halten. Sollte das Schicksal doch einmal eine Lücke im Sicherheitsdispositiv finden, lässt sich dank ausgeklügelter Versicherungsnetze aus dem Schaden wenigstens noch materiell Profit schlagen.

Das Bedürfnis nach Sicherheit, der Wunsch, alles im Griff zu haben, ist mehr als nachvollziehbar. Die Menschheit hat im Verlauf ihrer Entwicklung beträchtliche Energien dafür aufgewendet, vom Lebensgefühl des Steinzeitmenschen wegzukommen. Wenn der Homo erectus im Morgengrauen aus seiner Höhle kroch, schwante ihm, dass er auch an diesem Tag wieder eine gute Chance haben würde, sich im Magen eines Säbelzahntigers wiederzufinden, von einem feindlich gesinnten Keulenträger erschlagen zu werden oder als Folge einer Jagdverletzung innert Tagen am Wundbrand zu sterben. (Ironischerweise sorgt unser ausgeklügeltes, auf die Bewältigung solcher Situationen ausgerichtetes «archaisches» Hormon- und Neurotransmittersystem dafür, dass wir Extremzustände bei allem Sicherheitsfanatismus weiterhin suchen.)

Selbstredend ist es auch in der Medizin das Ziel, Sicherheit zu schaffen, alles unter Kontrolle zu bekommen. Die Erfolge können sich sehen lassen. Und doch ist nach wie vor kein Mensch davor gefeit, sich unversehens mit einer schweren körperlichen oder psychischen Erkrankung konfrontiert zu sehen und dadurch aus der vermeintlich sicheren Bahn geworfen zu werden. Die «Grenzsituation» bleibt Bestandteil des menschlichen Lebens.

Mit verschiedensten «Grenzsituationen» setzt sich in seinem gleichnamigen Buch [1], das erstmals 1981 erschienen ist, der Basler Psychiater und Psychoanalytiker Raymond Battegay auseinander. Angelehnt an Karl Jaspers, versteht der emeritierte Ordinarius für Psychiatrie und ehemalige Chefarzt der Psychiatrischen Universitätspoliklinik Basel darunter Situationen, «in denen ein Mensch entweder sich mehr oder weniger drastisch seiner Begrenztheit bewusst wird oder aber unbewusst an eine Grenze stösst, jenseits deren seine Existenz bedroht oder gar beendet wäre». Die betroffene Person erlebt Ein-

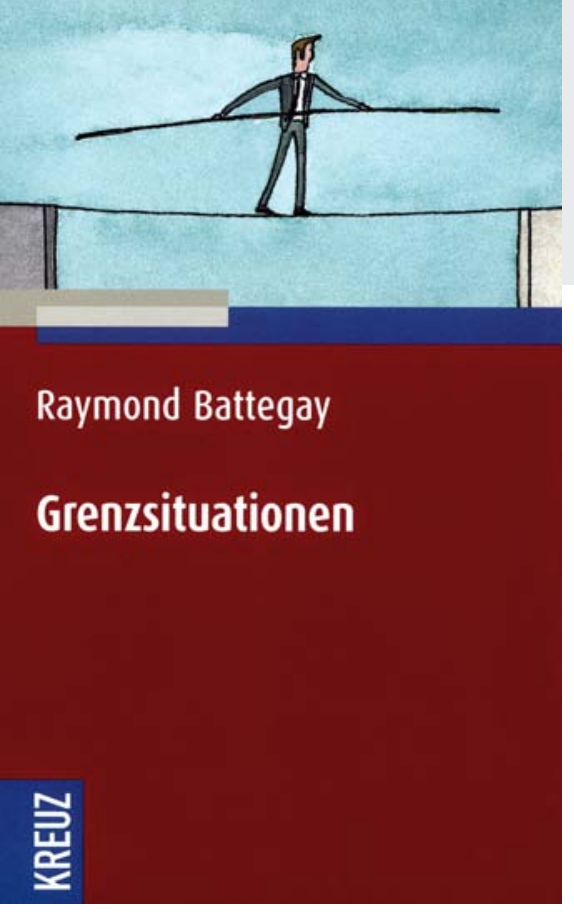

schränkungen, die sich nicht einfach beherrschen oder wegbefehlen lassen. «In einer solchen Grenzsituation kann einem Individuum, vielleicht erstmalig in seinem Leben, bewusst oder unbewusst aufgehen, welchen Wert für ihn/sie das Dasein verkörpert.»

Battegay spannt den Bogen thematisch über sein Fachgebiet im engeren Sinn hinaus, von $\mathrm{Zu}$ ständen mit Krankheitswert im psychiatrischen Sinn wie der depressiven, schizophrenen oder narzisstischen Grenzsituation bis hin zur Grenzsituation der sportlichen Spitzenleistung, der Grenzsituation der Einsamkeit oder der Grenzsituation bei HIV und Aids. Dabei schafft er es in bemerkenswerter Weise, die Charakteristika der jeweiligen Grenzsituation auf wenigen Seiten anschaulich darzustellen und mögliche therapeutische Ansätze anzudeuten. Und er öffnet den Blick von der Psychopathologie des Individuums hin zu gesamtgesellschaftlichen Befunden (deren kontextuelle Einbettung im isolierten Zitat allerdings verlorengeht): «Bei der Zunahme der computergesteuerten Reglementierungen in unserer Gesellschaft gewinnen wir immer mehr den Eindruck, dass wir Menschen ganz allgemein einem Zwangssystem unterworfen werden. Zwar wird es so möglich sein, die Administration grösserer Bevölkerungsgruppen zu erleichtern, doch wird sie damit auch entmenschlicht.»

Die in einer unprätentiös-klaren, aber durchaus eleganten Sprache gehaltenen Fallschilderungen und Kommentare belegen die auf immenser Erfahrung beruhende Autorität Battegays in der Sache. Auch wenn der psychoanalytische Hintergrund des Autors klar zutage tritt, kann das Buch von Leserinnen und Lesern mit unterschiedlichen fachlichen Voraussetzungen mit Gewinn gelesen werden.

Bruno Kesseli 